\title{
Ballooning for Biologists: Mission Essentials for Flying Life Science Experiments to Near Space on NASA Large Scientific Balloons
}

\author{
David J. Smith and Marianne B. Sowa
}

National Aeronautics and Space Administration, Space Biosciences Division, NASA Ames Research Center, Moffett Field, California 94035

\begin{abstract}
Despite centuries of scientific balloon flights, only a handful of experiments have produced biologically relevant results. Yet unlike orbital spaceflight, it is much faster and cheaper to conduct biology research with balloons, sending specimens to the near space environment of Earth's stratosphere. Samples can be loaded the morning of a launch and sometimes returned to the laboratory within one day after flying. The National Aeronautics and Space Administration (NASA) flies large unmanned scientific balloons from all over the globe, with missions ranging from hours to weeks in duration. A payload in the middle portion of the stratosphere $(\sim 35 \mathrm{~km}$ above sea level) will be exposed to an environment similar to the surface of Mars-temperatures generally around $-36^{\circ} \mathrm{C}$, atmospheric pressure at a thin $1 \mathrm{kPa}$, relative humidity levels $<1 \%$, and harsh illumination of ultraviolet (UV) and cosmic radiation levels (about $100 \mathrm{~W} / \mathrm{m}^{2}$ and $0.1 \mathrm{mGy} / \mathrm{d}$,
\end{abstract}

Key words: $\quad$ NASA Balloon Program;

Stratosphere; Large Scientific Balloons;

Payload; Aerobiology; Astrobiology; Space

Biology; Mars Analog Environment

Correspondence to: David J. Smith

NASA Ames Research Center

Space Biosciences Research Branch

M/S SCR-261-3

Moffett Field, CA 94035-0001

Telephone: 1-650-604-4819

E-mail: david.j.smith-3@nasa.gov respectively) - that can be obtained nowhere else on the surface of the Earth, including environmental chambers and particle accelerator facilities attempting to simulate space radiation effects. Considering the operational advantages of ballooning and the fidelity of space-like stressors in the stratosphere, researchers in aerobiology, astrobiology, and space biology can benefit from balloon flight experiments as an intermediary step on the extraterrestrial continuum (i.e., ground, low Earth orbit, and deep space studies). Our review targets biologists with no background or experience in scientific ballooning. We will provide an overview of large balloon operations, biology topics that can be uniquely addressed in the stratosphere, and a roadmap for developing payloads to fly with NASA.

\section{INTRODUCTION}

In 1783, a hydrogen balloon lifted off from Paris, France, starting the era of scientific ballooning. Across subsequent centuries, gasfilled balloons were used for research in astronomy, astrophysics, atmospheric science, and the acquisition of cosmic dust (Jones, 2014). Each of these disciplines recognized the flexibility and affordability of making balloon-borne observations at the edge of space-above 99.5\% of the Earth's atmosphere. To date, numerous discoveries can be credited to scientific ballooning, including the observation of an ozone hole at the South Pole (Solomon, 1999) and the confirmation of an expanding universe (de 
Bernardis et al., 1997). Biologists can follow the lead of other disciplines already engaged in scientific ballooning to achieve fast-tracked experiments within the fields of aerobiology, astrobiology, and space biology. Balloons offer many benefits: missions are about two orders of magnitude less expensive than the costs associated with launching a payload into orbit; balloons can lift massive payloads (up to $3600 \mathrm{~kg}$ ); flight schedules are more rapid and flexible than orbital opportunities; and balloon payloads are almost always recovered-not necessarily the case with experiments launched into space. With lower overall project costs, it is not unusual for a balloon payload to fly on multiple occasions, enabling progress that can be achieved only by consecutive missions.

Balloons fly around 28 to $48 \mathrm{~km}$ above sea level (ASL) in a portion of Earth's upper atmosphere called the stratosphere. While balloon flight experiments do not achieve microgravity, the stratosphere provides harsh environmental stressors that can also be found in low Earth orbit (LEO), interplanetary deep space, and the surface of other worlds (Adams et al., 2007; Smith, 2013). For instance, the stratosphere's rarified air contains high ultraviolet (UV) light levels, subzero temperatures, extreme dryness, and powerful oxidizing species-almost perfectly simulating conditions that would affect terrestrial biology on the surface of Mars (Schuerger and Nicholson, 2016; Smith, 2013). The stratosphere is also bombarded by a broad range of high energy particles at low doses, particularly in polar regions (Adams et al., 2007). Accordingly, the stratosphere is an analog environment and an incremental step along the path of characterizing how life traveling inside a spacecraft will respond to conditions someday encountered far away from Earth. Using the stratosphere, a variety of organisms and instruments can be evaluated at a faster rate than what can be currently achieved through International Space Station (ISS) flight opportunities. While hypobaric chambers and particle accelerating facilities may also be used to measure the effects of space-like environments on biology, ground simulations are often (1) expensive to perform, (2) volume limited, and (3) unable to accurately mimic dynamic sunlight levels while generating other conditions present in near space (e.g., extreme dryness and coldness).
Consequently, ground-based experiments tend to be short-lasting, small in size, and limited by artificial doses of radiation. In contrast, the stratosphere naturally produces a fuller suite of biological stressors expected in spacesimultaneously applied-including real sunlight and high energy particles. Considering the infrequency of spaceflight experiments and inherent limitations of ground facilities, some biological experiments would be better served through balloon missions to test hypotheses and hardware prior to orbital and/or deep space flights.

Our review aims to educate the biology research community about large scientific ballooning and provide logistical insight. We will cover the basics about balloon operations (Part 1: Ballooning Overview), before highlighting the kinds of scientific questions that can be examined in Earth's stratosphere (Part 2: Biology Questions Testable with Balloon Flights), and finishing with recommendations and resources for new teams pursuing biological balloon flights (Part 3: Considerations for Future Biological Experiments). Our focus is on large (up to $\sim 140$ $\mathrm{m}$ diameter), high-altitude ( $\sim 36 \mathrm{~km}$ ASL) scientific balloons flown by NASA; not smaller, hand-launched weather balloons that can also be used for biology experiments (e.g., BeckWinchatz and Bramble, 2014; Bryan et al., 2014) but have a limited payload lift capacity and lifetime. Although ballooning is an international activity, our review is specifically scoped for NASA missions that fly from a wide range of global locations. Before proceeding, we must emphasize a disclaimer: the following content does not represent priorities or policies of the NASA Balloon Program Office (BPO). Simply stated, our goal is to share lessons learned from biological ballooning-written from a scientific investigator's perspective- to educate teams interested in flying life science experiments to the stratosphere.

\section{PART 1: BALLOONING OVERVIEW}

\subsection{History of the NASA Balloon Program}

The NASA BPO is located at Goddard Space Flight Center's Wallops Flight Facility (WFF) at Wallops Island, Virginia (https://sites.wff.nasa. gov/code820/). Managed within the Suborbital and Special Orbital Projects Directorate (Code 
800), the BPO (Code 820) oversees operations for a portfolio of 10 to 16 annual missions sponsored and approved by NASA's Science Mission Directorate (SMD) Astrophysics Division. NASA's balloon launch and flight operations are conducted by the BPO prime contractor at the Columbia Scientific Balloon Facility (CSBF) in Palestine, TX. The CSBF is currently staffed by Orbital ATK (Greenbelt, MD) and includes approximately 75 personnel who support engineering, balloon launch, flight and recovery operations, flight support systems fabrication, and administration. Up to date information on the NASA balloon schedule, operations, documentation, photos, and points of contact can be found at the CSBF website (http://www.csbf.nasa.gov/). In fact, much of the information contained in Section 1 has been synthesized from documentation available on the website (CSBF, 2016a; CSBF, 2016b; NASA, 2014a; NASA, 2014b).

NASA BPO/CSBF launch sites are shown in Figure 1. Locations in both hemispheres provide science teams polar and mid-latitude flight trajectories, including the recovery of balloons and science systems. Annually, BPO/CSBF conduct 2 to 3 missions launched from McMurdo, Antarctica in the December to January timeframe; 6 to 9 missions launched from Fort Sumner, NM, in the August to October timeframe; and 2 to 3 missions launched from Palestine, TX, in June. Based on science requirements, the BPO budget supports one campaign from Wanaka, New Zealand, Alice Springs, Australia, or Esrange located at Kiruna, Sweden.

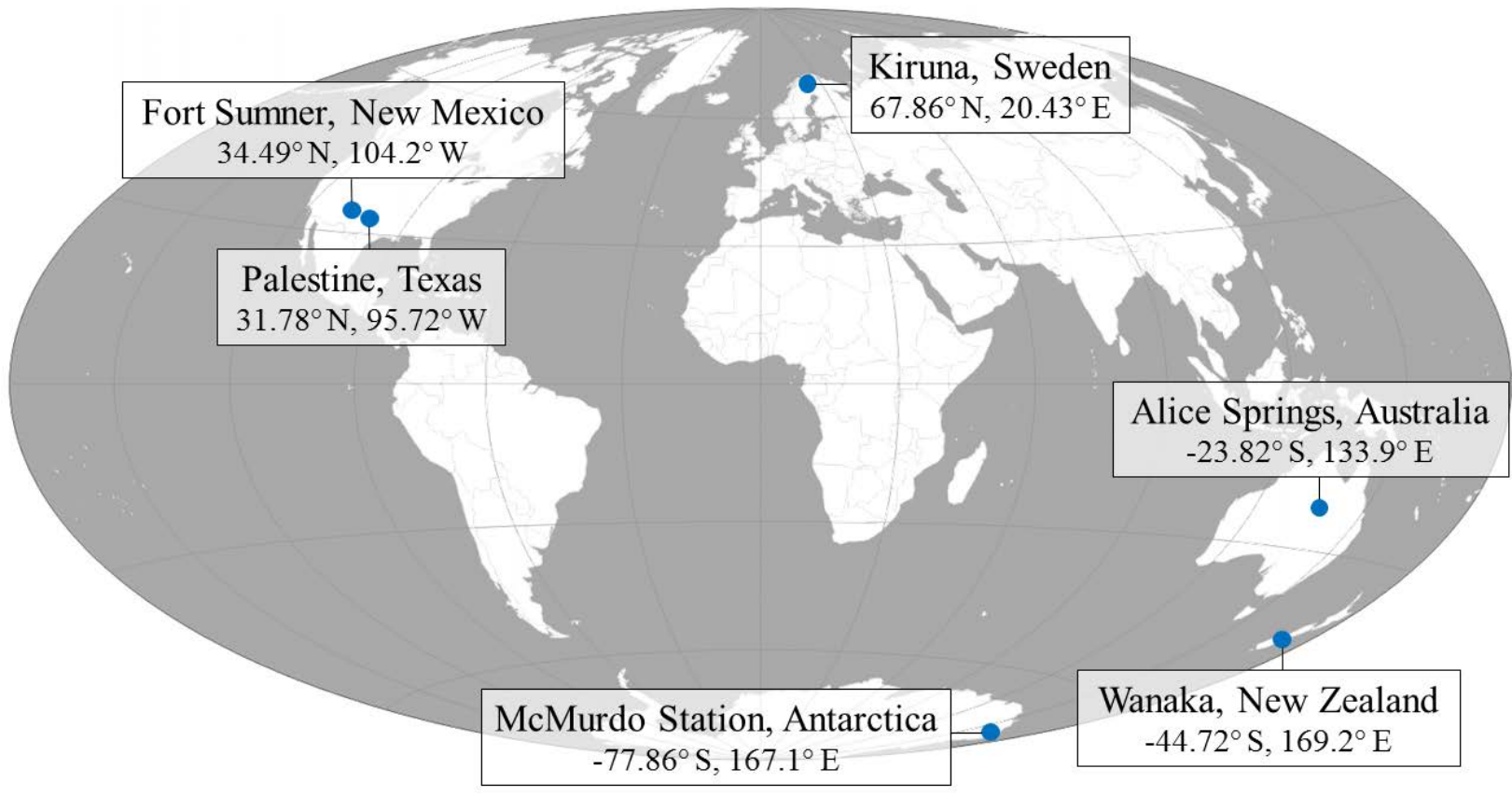

Figure 1. Launch site locations of the NASA Balloon Program. Map backdrop image courtesy of http://www.freeworldmaps.net.

\subsection{Balloon System Overview, Launch, and Landing}

Before designing experiments, new investigators should have a basic understanding of balloon systems and flight operations. NASA balloon flight configurations can vary depending upon specific mission requirements, but in the simplified narrative below we explain key system components. Figure 2 depicts a typical pre-launch configuration. Large NASA balloons are composed primarily of thin-film polyethylene (0.02 mm thick) with load-bearing members, and filled using large volumes of helium (0.11 to 1.11 
million cubic meters). The balloon flight train is comprised of a balloon, parachute, cable ladder, and scientific payload. A payload consists of a gondola with one or more instruments and will include NASA support instrumentation and telemetry systems.

Weather plays a critical role in launch operations. NASA BPO and CSBF have strict guidelines on acceptable forecast conditions and closely monitor winds right up to the moment of launch. Columbia Scientific Balloon Facility (CSBF) meteorologists provide forecasts, realtime analysis, and weather monitoring on launch day to include trajectory updates and descent vectors for end-of-mission planning. Wind conditions must be sufficiently slow and stable before the launch director proceeds with inflation of the balloon. Launch is conducted during periods of relatively light surface and low level wind conditions that do not exceed $6 \mathrm{~m} / \mathrm{s}$. Inflations can take up to an hour depending upon balloon size. During the inflation process, the balloon remains attached to the spool vehicle and helium tanks on the flight line are used by launch team personnel to funnel gas through inflation tubes connected to the balloon. The uninflated portion of the balloon remains folded and laid out on the ground in the direction of the launch vehicle. The science payload is attached to a mechanical assembly connected at the end of the launch vehicle boom, released at time of launch to allow the balloon to ascend. Once inflation is complete, the launch director calls for spool release, then the inflated portion of the balloon rises, carrying the parachute and flight train vertically over the payload; at the same time, the launch director calls for final alignment of the launch vehicle and the prevailing wind direction. After the balloon-parachute-flight train assembly is directly overhead and slightly forward of the launch vehicle, the payload is released by a manual command sent to the mechanical launch pin fitting. Typical time to launch from the end of the balloon inflation is $10 \mathrm{~min}$.

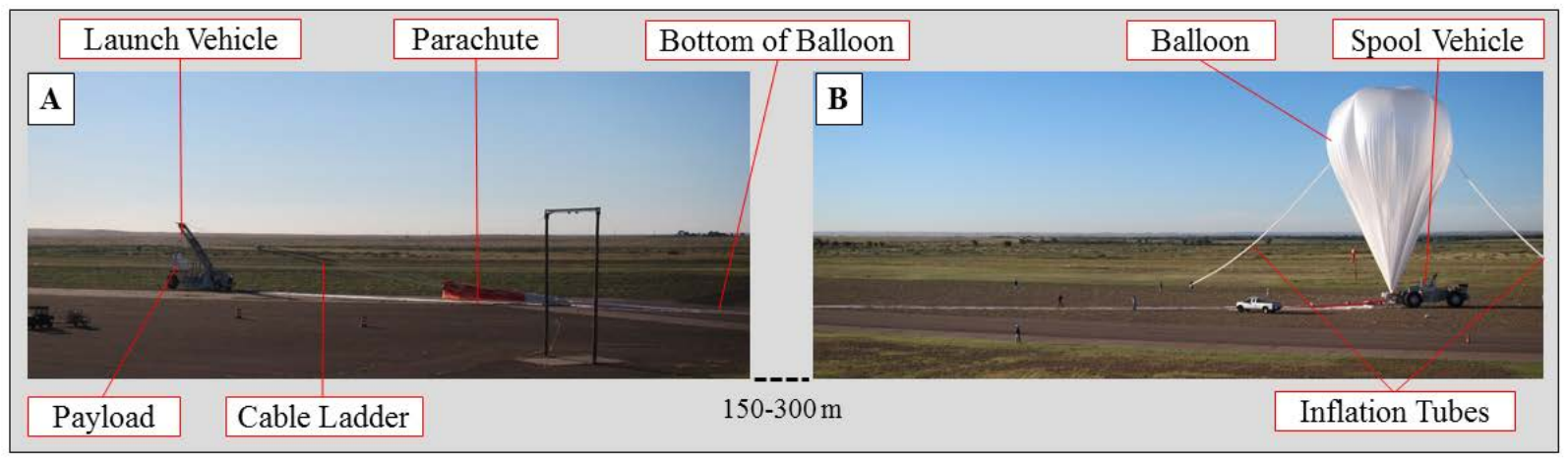

Figure 2. Balloon system overview at launch site in Ft. Sumner, NM. Note pickup truck and ground personnel for relative scale. The entire length of the flight system is not depcited but ranges from 150 to 300 m. Photos taken at launch of Long Duration Balloon Technology Flight \#651 in August 2014.

As the balloon ascends ( $\sim 240 \mathrm{~m} / \mathrm{min}$ on average) due to positive buoyancy, it expands through the progressively rarefied atmosphere, stretching up to $140 \mathrm{~m}$ diameter in size. It can take up to $2.5 \mathrm{~h}$ to reach a float height of 30 to 40 km ASL, with stability achieved by neutral buoyancy and release of extra gas through vents (depending on the type of balloon; see Section 1.4). Some NASA payloads are launched with near real-time, stationary, or remote-controlled cameras that broadcast video streams from the gondola when a balloon mission is flying. Cameras can be a critical tool for monitoring ascent/descent and nominal balloon or payload performance. CSBF provides real-time position updates during ascent and communicates with the science team once a float altitude has been achieved. When a mission is completed, the parachute and payload are separated from the balloon by pyrotechnics, and a panel on the balloon is ripped open to release the helium. The payload is separated from the flight train via a 
termination fitting that is commanded to release the suspended parachute/science payload. The gondola returns to the ground on a nylon, flat circular parachute up to $48 \mathrm{~m}$ diameter (depending on the mass of the payload) and the balloon freefalls to the ground. Before committing to a termination, CSBF coordinates with air traffic control, musters a chase aircraft for surveillance (on domestic missions), deploys recovery crew, and assesses the predicted descent trajectory to achieve the lowest risk to the public and, secondarily, to the mission. Following a 40 to 50 min descent, the payload will reach the ground with an impact cushioned by crush pads on the base of the gondola. A separator unit located on the flight train above the payload releases the parachute upon landing to prevent dragging that could occur from surface winds.

A combination of aircraft and ground vehicles will be used by the BPO/CSBF recovery team. Recovery times are typically several hours to one day for conventional, domestic missions; it can take longer (up to a few weeks) for international missions. Some Antarctic missions may not be fully recovered until the following year; under such circumstances, partial recoveries of small articles and onboard data will be attempted. Science personnel are often allowed to accompany the BPO/CSBF recovery personnel to execute special handling requirements. A set of basic CSBF-generated flight data can be provided upon request to the science team within several days following a flight, with other specially requested reports (e.g., detailed meteorology measurements) delivered if pre-approved in the flight application process (see Section 3.2). The general flight report includes measurements at specific intervals taken from the balloon gondola including altitude (by global positioning system and pressure), atmospheric pressure, air temperature, down-looking radiometer readings, and latitude and longitude.

\subsection{Launch Site Locations and Balloon Trajectories}

Six active sites are currently used by NASAFt. Sumner, NM, and Palestine, TX, in the United States; and internationally at (Esrange) Kiruna, Sweden; Alice Springs, Australia; Wanaka, New Zealand; and McMurdo Station, Antarctica. Conventional missions are launched from Fort
Sumner, Palestine, Esrange, and Alice Springs. Long Duration Balloon (LDB) missions are launched from McMurdo and Esrange; Super Pressure Balloon (SPB) missions are launched from Wanaka and McMurdo (see Section 1.4). In early 2016, NASA launched the Compton Spectrometer and Imager (COSI) astrophysics payload from Wanaka with a SPB that traveled eastward on a stratospheric cyclone, circling the world after $14 \mathrm{~d}$ and achieving $46 \mathrm{~d}$ aloft (Chiu et al., 2015). Global circumnavigations between 9 to $12 \mathrm{~d}$ are also achievable for flights launched from William's Field near McMurdo Station, Antarctica, located on the Ross Ice Shelf (Jones, 2012). Given the extremely remote location, Antarctic balloon flights require comprehensive planning with the NASA BPO and National Science Foundation (NSF), which manages United States Antarctic Program. Since 1991, the NASA-NSF partnership has launched 45 balloon flights from Antarctica, with each mission averaging a float time of about $18 \mathrm{~d}$. Antarcticbound balloon teams generally arrive at McMurdo Station for pre-launch preparations in early November. Flights from Antarctica drift west and payloads can be lost or delayed in a full recovery due to unforgiving terrain and a short operating season usually ending by February.

Experimenters must work closely with NASA $\mathrm{BPO} / \mathrm{CSBF}$ to determine specific requirements for float trajectories and operational areas of interest. Balloon trajectories are determined by stratospheric winds. Guided trajectory control of balloons is a desired capability, but to date, no proven onboard steering control system exists for NASA heavy lift balloon platforms. Long range trajectory control has been demonstrated for smaller balloon systems (D. Gregory, personal communication); however, such capability currently does not exist for large NASA scientific balloons. Stratospheric winds normally tend toward zonal (latitudinal) directions based on seasonally-established, polar upper-level highs and lows. Summer stratospheric winds are easterlies (east to west) whereas winter stratospheric winds are westerlies. Twice each year, stratospheric turnaround occurs in the spring and fall when upper atmosphere winds decrease, becoming light and variable, and then increasing in the opposite direction for the follow-on summer easterlies or winter westerlies. Stratospheric 
turnaround typically occurs over a 7 to $10 \mathrm{~d}$ period during which time NASA conventional flights can be executed to achieve upwards of 24+ $\mathrm{h}$ within line of sight of the launch location.

\subsection{Balloon Capabilities}

NASA offers a variety of standard balloon designs that support suspended masses ranging from a few $\mathrm{kg}$ up to $3630 \mathrm{~kg}$, spanning altitude ranges of approximately $29 \mathrm{~km}$ to $45 \mathrm{~km}$ ASL. Float altitude is determined by the size of the balloon and the entire mass of the system. Required flight support systems make up a significant portion of the mass budget. For example, a 29.47 million cubic feet (MCF) balloon design can carry its own mass plus 1814 kg suspended mass to a standard pressure altitude of $\sim 39 \mathrm{~km}$ ASL. If a lighter suspended mass is flown, the system will fly higher. NASA balloon missions are classified as Conventional Missions that utilize Zero Pressure Balloons (ZPB) with durations of a few hours to $24+\mathrm{h}$ and controlled by continual line-of-sight from the launch site or downrange ground stations; Long Duration Balloon (LDB) Missions that also fly ZPBs but over the horizon with flights lasting days to weeks controlled from the CSBF Operations Control Center (OCC) located at Palestine, TX, via satellite relayed telemetry; and finally, Super Pressure Balloon (SPB) Missions, still under development, with the goal of achieving $100+d$ flight durations (also controlled from the CSBF OCC). Experimenters can work with the NASA $\mathrm{BPO} / \mathrm{CSBF}$ during the flight application package (see Section 3.2) to determine the appropriate balloon vehicle based upon science requirements. Most new payloads are tested with a conventional balloon launching from Ft. Sumner, NM, or Palestine, TX, before flying on a long duration mission outside of the United States.

With ZPB-the majority of NASA BPO missions-there is no differential pressure between the interior and exterior environment at the base of the balloon. Zero pressure balloons incorporate vent ducts that open near the bottom of the balloon, used to release "free-lift" gas while at float. For example, mission planners calculate the amount of helium needed to carry the balloon and all suspended mass to the target float altitude, and then an additional $10 \%$ to $12 \%$ of helium is added to this amount at the time of inflation. As the balloon approaches its float altitude, the extra free-lift gas vents off. Balloons are thermal vehicles, so altitudes vary according to the radiation environment and helium leak rate over time. Because ZPB incorporate open vents, they are prone to loss of helium during diurnal transitions. Expendable ballast is used to mitigate loss of altitude going into sunset transition and through the night. Since the amount of ballast that can be flown also comes out of the suspended mass budget, there is a tradeoff between how much ballast can be carried and the science payload mass; thus, ZPB flight durations are limited by the amount of expendable ballast available. Polar orbits provide a more stable radiant environment for $\mathrm{ZPB}$, which allows long durations with little altitude variability. The Super-TIGER LDB mission in 2013 over Antarctica recorded the longest flight in the history of the NASA balloon program at $55 \mathrm{~d}$ (Ward, 2013).

NASA is developing a SPB vehicle ultimately intended to offer 'ultra-long duration' flights (up to $100+$ d) at middle latitudes. Early test flights show promise (Cathey, 2008) and NASA has continued to make significant progress. The SPB has a robust design to maintain differential pressures on the order of $\sim 0.08$ to $0.15 \mathrm{kPa}$ during nominal day-night operations. Since the SPB does not lose as much helium over the course of a multi-day flight, as depicted in Figure 3, it keeps a relatively level altitude compared to the ZPB. Today, SPB are currently being tested to support $1000 \mathrm{~kg}$ of science to a float altitude of $33 \mathrm{~km}$ ASL utilizing a 0.5 million cubic $\mathrm{m}$ volume design. NASA is investigating a larger volume of gas ( 0.74 million cubic $\mathrm{m}$ of helium) to support $1000 \mathrm{~kg}$ of science to a float altitude of $35 \mathrm{~km}$ ASL (G. Garde, personal communication). In 2015, the BPO qualified an 18.8 MCF SPB with 4 test flights achieving a 32+ d flight duration; the following year, a SPB test flight achieved a 46+ d duration (D. Gregory, personal communication).

\section{PART 2: BIOLOGY QUESTIONS TESTABLE WITH BALLOON FLIGHTS}

\subsection{Overview}

Broadly, there are three categories of life science experiments that can benefit from large scientific balloon flights. The first we call 


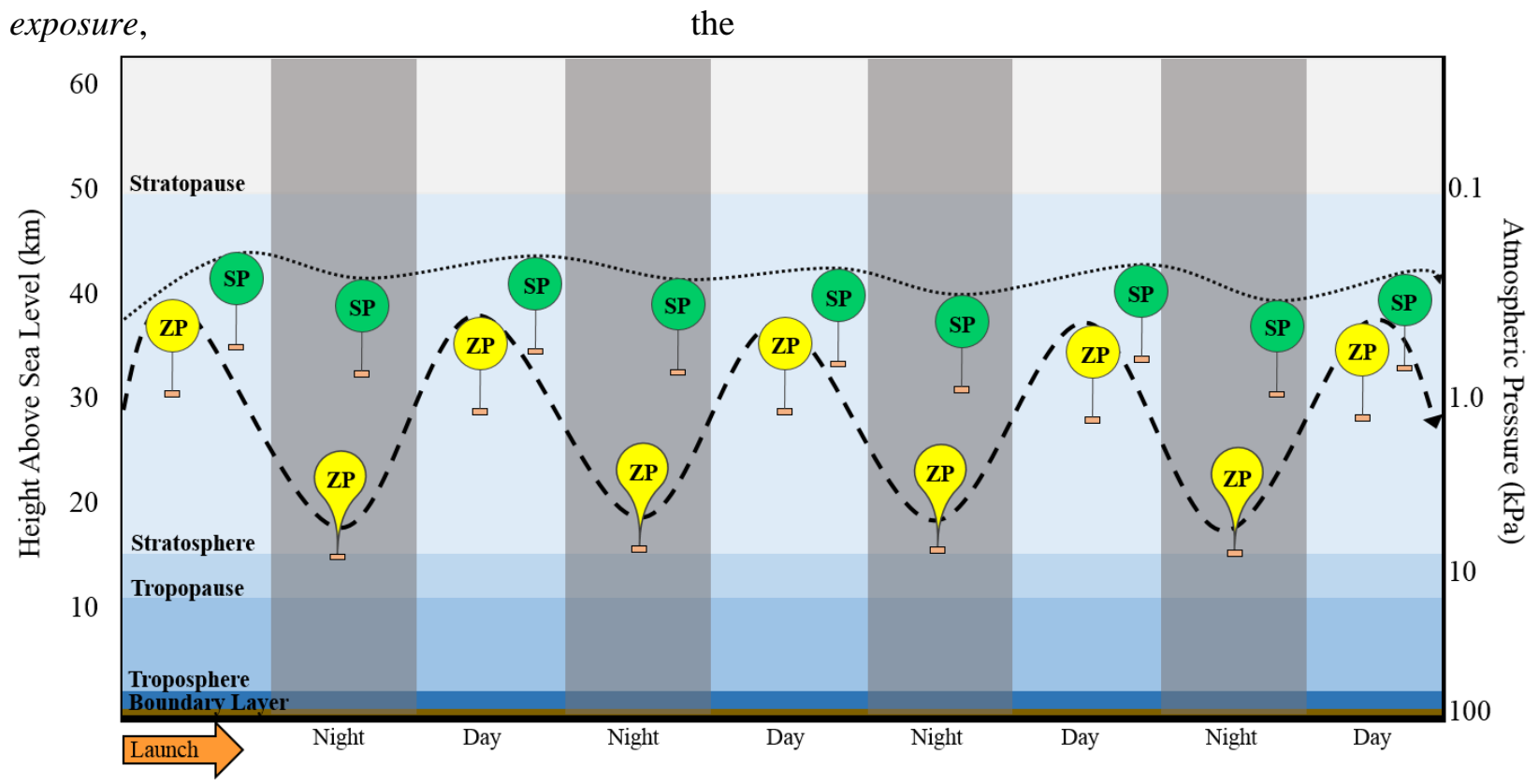

Figure 3. Generalized profile of Earth's atmosphere (not to scale) and the diurnal altitude variations between NASA Zero Pressure (ZP) Balloons and Super Pressure (SP) Balloons.

simplest form of performing biological science in the stratosphere-essentially, transporting known quantities of model organisms to the upper atmosphere and returning samples to the surface for subsequent laboratory analyses. Most previously flown biological balloon experiments are exposure-class. More challenging and less common are collection experiments that aim to acquire bioaerosols floating at altitudes far above the Earth's surface. A final technology category exists for biological payloads-it includes life science instruments that could benefit from a performance evaluation in the harsh near space conditions of the stratosphere.

The following subsections summarize the stratospheric environment, describing parallels to LEO, deep space, and the surface of Mars that build a compelling case for biological balloon flights. We then address the benefits and limitations of ground-based facilities for performing space radiation biology experiments, and ultimately, the need to leave the ground for more robust research results. We conclude by discussing relevant scientific topics in the fields of aerobiology, astrobiology, and space biology for future balloon experimenters pursuing exposure-, collection-, or technology-class payloads.

\subsection{The Stratosphere}

\section{Overview of physical conditions}

Earth's stratosphere spans from about 17 to 50 $\mathrm{km}$ ASL containing air that is thinner, drier, and generally colder than the tropospheric air below. Gases and aerosols are the main constituents of the stratosphere; most weather and precipitation occurs in the troposphere. The background aerosol layer in the stratosphere consists primarily of binary sulfuric acid-water aerosol droplets (Jacob, 1999). Atmospheric oxygen is converted into ozone by powerful light reactions in the stratosphere, creating a layer essential for shielding life on the Earth's surface from destructive UV radiation. The troposphere is turbulent and well mixed; however, physical properties of the stratosphere limit convection. Consequently, there is little internal mixing or exchange with the troposphere (Jacob, 1999). However, surface, marine, and anthropogenic aerosols can reach the stratosphere by strong convection, resulting in upward winds generated by thunderstorms, monsoons, hurricanes, and 
cyclones (Smith, 2013). Volcanic eruptions, electrostatic levitation, tropopause folding, convective overshooting, and even commercial airplane traffic can also inject aerosols into the stratosphere. Meteors and rocket launches may contribute foreign aerosols into the stratosphere at rates unknown but probably minor. Eventually, stratospheric aerosols return to the surface by Brewer Dobson circulation moving air masses towards the poles - the fallout process takes anywhere from months to years, determined mostly by the size of the aerosol.

\section{Similarity to extraterrestrial environments}

At altitudes above most of the ozone layer, where large NASA balloons float, there may be no better natural analog for Mars surface conditions. For example, recently acquired data from LDB Test Flight \#667NT in October 2015 recorded float conditions at $\sim 32 \mathrm{~km}$ ASL reaching $0.962 \mathrm{kPa},-73.1^{\circ} \mathrm{C},<1 \% \mathrm{RH}$, and modeled UV levels totaling $86.6-109 \mathrm{~W} / \mathrm{m}^{2}$ for up to $8 \mathrm{~h}$ (Khodadad et al., 2017). Accordingly, summer conditions at equatorial regions on Mars (Nicholson et al., 2005; Schuerger and Nicholson, 2006) are arguably more habitable than Earth's stratosphere. Although Mars is illuminated with less light due to its distance from the Sun, under clear-sky conditions the surface of the Red Planet receives about 3 orders of magnitude more UV irradiance than the surface of the Earth (Cockell et al., 2000), particularly in biocidal UVC wavelengths 200 to $280 \mathrm{~nm}$ that damage DNA. The rarified martian atmosphere $(\sim 0.7 \mathrm{kPa}$ on average) has fewer chemical species capable of UV absorbance or attenuation (Kuhn and Atreya, 1979; Zurek et al., 1992). Nicholson et al. (2005) generalized fluence rates for the surface of Mars at approximately 3.18 and $8.38 \mathrm{~W} / \mathrm{m}^{2}$ for UVC and UVB, respectively. These values are similar to UV levels measured by Kylling et al. (2003) who flew a radiometer to $30.5 \mathrm{~km}$ ASL on a balloon mission over France $\left(\sim 44.5^{\circ} \mathrm{N}\right)$.

The composition of an ionizing radiation environment that a biological payload will experience during a balloon flight is complex, changing with both altitude and inclination. For instance, at higher inclinations the number of galactic cosmic ray (GCR) particles that make it through the magnetosphere is higher due to the orientation of the magnetic field. In a recent
NASA balloon flight experiment launched September 2015 (Flight \#666N from Ft. Sumner, NM), the Radiation Dosimetry Experiment (RaD$\mathrm{X})$ was sent to $36.6 \mathrm{~km}$ ASL to test an ionizing radiation instrument suite. Average dose rates in the stratosphere were approximately $0.064 \mathrm{mGy} / \mathrm{d}$ (Mertens et al., 2016), slightly lower than recent measurement by the MSL rover on the surface of Mars, 0.18 to $0.225 \mathrm{mGy} / \mathrm{d}$ (Hassler et al., 2014). The average linear energy transfer (density of ionizations per unit length) was found to increase as altitude increased from 24.3 to $36.7 \mathrm{~km}$ (Mertens et al., 2016) probably due to heavy ions ( $Z=6-28)$ (NCRP, 1995). The contribution of ion particles to the total exposure dose is not based solely on abundance but is proportional to $\mathrm{Z}^{2}$ (NCRP, 1989). Despite relatively low abundance, $\mathrm{Z}$ energetic particles have a high ionization potential and will be the main contributors to risk beyond LEO (Cucinotta and Durante, 2006). However, at high altitudes $\mathrm{Z}$ energetic particles will undergo fragmentation to produce neutrons with the highest density of ionizations occurring at altitudes of 20 to $25 \mathrm{~km}$ ASL (NCRP, 1995).

Neutrons will be the most hazardous radiation for multicellular biological studies in the stratosphere (Schimmerling, 2011). Understanding the biological response to neutron exposures is also relevant to future deep space human missions due to interactions of energetic particles with spacecraft components. Some shielding materials may give rise to secondary fragmentation products that could be more damaging than the primary radiation field (NCRP, 2006). Solar particle events are also capable of causing large fluxes in the high energy proton spectra (Schimmerling, 2011). A characterization of stratospheric radiation compared to other spaceflight environments including LEO and deep space was reviewed by Adams et al. (2007). Polar balloon flights would provide the largest levels of ionizing radiation to biological balloon payloads due to the window of energy-intense particles penetrating stratosphere latitudes above $70^{\circ}$.

\subsection{Limitations of Ground Facilities for Simulating Near Space Conditions}

It is difficult to replicate the overall complexity of radiation levels in the stratosphere; however, individual components of the radiation environment can be studied using ground-based 
facilities. There are a number of useful UV exposures methods (described by Smith et al., 2011) but no single lamp or group of lights can mimic a drifting solar zenith or complex surface interaction effect. Low scatter test facilities are available at various locations to study the effects of neutrons and energetic ions on biological samples, for example, at Pacific Northwest and Lawrence Livermore National Laboratories. Such facilities use a radionuclide source (e.g., ${ }^{252} \mathrm{Cf}$ ) to generate neutrons. The radiation spectrum produced at ground facilities will be monoenergetic or cover a narrow but discreet energy range due to the nature of the source. For spaceflight exposures, low dose rate conditions (7 to $10 \mu \mathrm{Gy} / \mathrm{h}$ ) remain practical at these facilities with few restrictions to experimental size, depending on the source age and mounting distance from the biological specimens.

In order to study the effects of GCR and solar particle events on both biology and physics, NASA has developed a specialized radiation exposure facility at Brookhaven National Laboratory (https://www.bnl.gov/nsrl/). The NASA Space Radiation Laboratory (NSRL) is capable of generating a range of ions from protons to uranium at relevant energies observed beyond LEO (from $50 \mathrm{MeV}$ to $1000 \mathrm{MeV}$, depending on the ion). Beam target size is limited to about $20 \mathrm{x}$ $20 \mathrm{~cm}^{2}$ which can be a limitation for experiments requiring large hardware for biological samples. Current beamline developments should permit more complex mixed ion exposures in the future, but the inclusion of the full range of combined stratospheric stressors that effect biological responses cannot be easily replicated at NSRL (including ultralow temperatures and pressure, ultrahigh dryness and UV levels). Additionally, the need to perform studies at very low dose rates to replicate the space environment is not always practical at NSRL due to access limitations and cost. The use of ground exposure facilities should be regarded as complimentary to balloon flight experiments to measure the integrated effects of primary ion species, energy profiles, and dose response in a more complex, systematic fashion.

\subsection{Aerobiology Research Topics in the Stratosphere}

There is an emerging body of evidence that microorganisms (bacteria, fungi, viruses, archaea, and protista) ride free tropospheric and stratospheric wind currents (Barberán et al., 2015; Deleon-Rodriguez et al., 2013; FröhlichNowoisky et al., 2016; Myriokefalitakis et al., 2017; Smets et al., 2016; Smith et al., 2012, 2013). Most airborne microbes (also referred to as 'bioaerosols' and 'aeroplankton') are cotransported with dust emanating from the largest deserts on Earth (Acosta-Martinez et al., 2015; Kellogg and Griffin, 2006). In addition to dust, viable cells associated with marine environments, soot, wastewater, farmlands, and other natural and artificial sources have been detected at altitudes ranging up to $36 \mathrm{~km}$ ASL (Bryan et al., 2014; Smith, 2013), sometimes thousands of kilometers downwind from modeled points of origin. Aerosol type, chemical species mixing ratios, kinematic back trajectories, and microbial identity have been utilized as independent methods for determining the transport history of bioaerosols dispersed vast distances on upper atmospheric winds (Creamean et al., 2013; Favet et al., 2012; Smith et al., 2013). The influence of high altitude transport on airborne microbes and consequences to ecosystems where non-native species get deposited is fundamentally unknown.

Atmospheric bridges connecting continents and corridors providing gene flow could be directly monitored with NASA balloon flights. Previous ground or alpine studies have been restricted to monitoring the dispersal of microbes from source regions (Maki et al., 2013; Puspitasari et al., 2015; Yamaguchi et al., 2012, 2016) or the arrival of bioaerosols at downwind locations (Smith et al., 2012, 2013), as opposed to sampling along the route itself. While NASA aircraft missions have flown narrow sweeps to capture bioaerosols in transit (Deleon-Rodriguez et al., 2013; Griffin, 2004, 2007; Smith et al., 2009), no study has examined transport across an entire float range. Atmospheric bridges can span thousands of kilometers and take 7 to $10 \mathrm{~d}$ of travel time for transpacific dust (Smith et al., 2013) and 5 to $7 \mathrm{~d}$ of travel time for transatlantic dust (Griffin et al., 2006; Kellogg and Griffin, 2006). A NASA balloon could be launched on an intercontinental trajectory, either measuring airborne microbes along the bridge (i.e., a collection-class experiment) or intentionally carrying previously isolated atmospheric microorganisms (i.e., an exposure-class experi- 
ment), to monitor population survivability and response profiles. Examining the dynamics along an atmospheric bridge-not just the "on-ramp" or "off-ramp" like other studies published to date-is of central importance to the field of aerobiology and uniquely testable with balloon flights.

Interpreting results from a stratosphere ground simulation, Smith et al. (2011) noted that an atmospheric bottleneck effect might influence microbial speciation rates. With routine, global dispersal along UV-bombarded atmospheric corridors, adaptations for radiation resistance and DNA-repair possessed by some bacterial taxa could have emerged from persisting bioaerosol species. While complicated evolutionary histories cannot be disentangled with balloon flights alone, measurements of microbial mutation rates with exposure-class experiments might be a simple, testable step towards examining broader evolutionary hypotheses. Alarmingly, more dust travels in the upper atmosphere with each passing year due, in part, to desertification and higher emissions from anthropogenic sources (Randel and Jensen, 2013; Yu et al., 2012). Some groups have postulated that the timing of outbreaks of disease, including foot-and-mouth, bluetongue virus, and Kawasaki, might be correlated with the arrival of intercontinental dust plumes (Ballester et al., 2013; Burns and Cayan, 2017; Fernstrom and Goldblatt, 2013; Griffin et al., 2001). With potentially significant economic and public health outcomes at stake, there is a clear need for future balloon experiments measuring unknowns associated with global bioaerosol transport.

Scientific ballooning provides the most promising method of performing a comprehensive stratospheric census or characterizing ecological consequences. Aerobiological exploration, historically, has been constrained by a shortage of sampling opportunities, preventing systematic studies across time and space. For instance, only three NASA aircraft missions have collected stratospheric microbes (Deleon-Rodriguez et al., 2013; Griffin, 2004; Smith et al., 2009). Balloons offer a longer time aloft and at higher altitudes than aircraft can travel, plus the ability to carry more weight (and power) than most aircraft. Bryan et al. (2014) described a bioaerosol collector that flew on a small $(2.7 \mathrm{~kg})$, handlaunched meteorological weather balloon and recovered viable microorganisms from an altitude of $38 \mathrm{~km}$ ASL. A similar, scaled-up system could be flown on a large NASA scientific balloon to collect aerobiological samples. Cosmic dust collectors (Brownlee, 1978; Brownlee et al., 1973) could also be repurposed for aerobiology studies, similar to what Griffin (2004) and Smith et al. (2009) established with NASA ER-2 aircraft flights at $20 \mathrm{~km}$ ASL.

\subsection{Astrobiology Research Topics in the Stratosphere}

Characterizing habitable environments was included in the recently released NASA Astrobiology Program strategy (NASA, 2015). Understanding the limits of life in one of Earth's most extreme environments-the upper atmosphere-is directly aligned with the research topic of habitability. Insight into the type of microorganisms capable of surviving in the stratosphere and underling protection or repair mechanisms can guide the search for life in extraterrestrial habitats (Smith, 2013).

Past astrobiology research has used environments in Antarctica (e.g., Wynn-Williams and Edwards, 2000) and the Atacama Desert (e.g., McKay et al., 2003) to study the Mars environment by analogy (Preston and Dartnell, 2014), but there are significant limitations to these environments. First, atmospheric pressure on the surface of Earth is about two orders of magnitude higher than it is on Mars. Second, the UV radiation levels on the surface of our planet are substantially lower than conditions expected on Mars due to the absorption of low wavelength UV by Earth's ozone layer. Rarefied atmosphere and higher radiation levels, alongside other biocidal conditions in the stratosphere, including severe dryness and coldness, make it more Mars-like (Schuerger and Nicholson, 2016; Smith, 2013). Therefore, teams testing microbial responses to stressors expected at Mars could more robustly evaluate psychrophiles, hypobarophiles, xerophiles, and radiation-tolerant species in Earth's stratosphere where a combination of simultaneously applied biocidal factors exist. Considering these advantages, a NASA experiment called Exposing Microorganisms in the Stratosphere (E-MIST) flew twice with the BPO (Khodadad et al., 2017; Smith et al., 2014) to determine how bioburden on spacecraft sent to Mars can withstand conditions that will be met 
upon arrival. Although Mars-bound, robotic spacecraft are cleaned before launch, hitchhiking bacteria remain in low concentrations across hardware (Benardini et al., 2014; Vaishampayan et al., 2013). The E-MIST payload shown in Figure 4 carried known quantities of endospores into the stratosphere that were originally isolated from a NASA cleanroom (Kempf et al., 2005; Link et al., 2004), measuring survivability and DNA damage of stratosphere-exposed samples compared to ground and flight controls (Khodadad et al., 2017).

Attempting to determine the upper altitude limit of Earth's biosphere is another understudied astrobiology-relevant research topic made possible by scientific ballooning, since it is important to understand the types of environments to conduct the search for extraterrestrial life. At what altitude the biological signal disappears, and how the concentration of bioaerosols changes with distance above the Earth's surface are key unknowns today. Up to about $49 \mathrm{~km}$ ASL, balloons can be used to collect bioaerosols through an entire column of air on ascent or descent. A number of international balloon missions have flown stratospheric expeditions (Narlikar et al., 2003; Shivaji et al., 2006; Wainwright et al., 2003), but contamination control procedures and the origin of bioaerosols collected were not comprehensively discussed. More recently, Della Corte et al. (2014) developed a payload called DUSTER (Dust in the Upper Stratosphere Tracking Experiment and Retrieval) for capturing aerosols at 30 to $40 \mathrm{~km}$ ASL. The first DUSTER flight was launched in April 2011 from Esrange (Kiruna, Sweden) by the Centre National d'Etudes Spatiales, collecting 26 stratospheric dust particles and morphologies resembling fungal spores during a $5.7 \mathrm{~h}$ balloon flight (Della Corte et al., 2014). The DUSTER payload and other emerging stratospheric microbiology hardware developed by research teams at Louisiana State University (N. Bryan, personal communication) could enable a deeper examination of the boundary of Earth's biosphere using large scientific balloons.

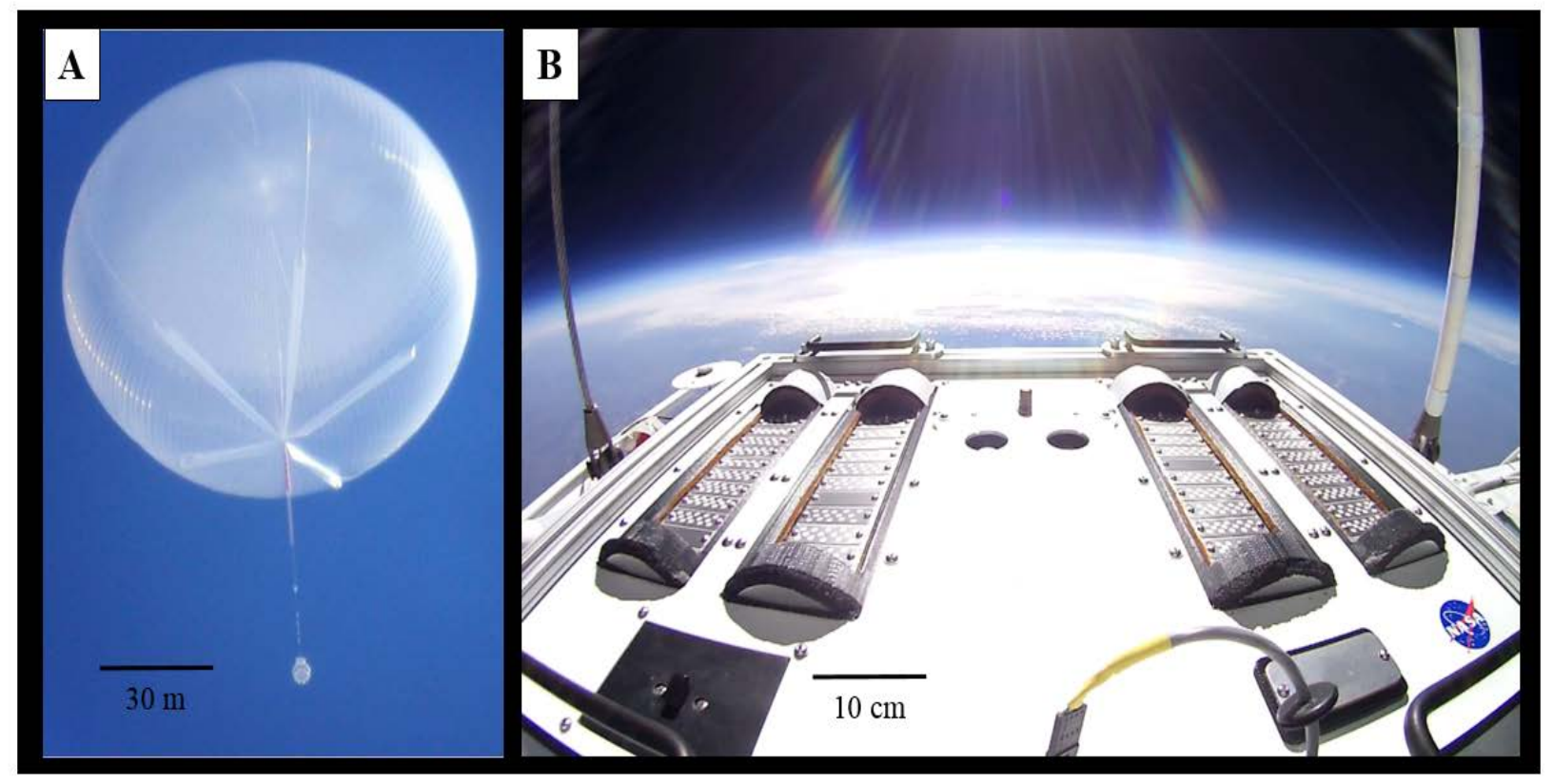

Figure 4. (A) A large NASA balloon at float in the stratosphere carrying a scientific payload, as viewed from a chase aircraft; (B) The Exposing Microorganisms in the Stratosphere (E-MIST) payload, flown most recently in October 2015 (Khodadad et al., 2017), was an exposure-class experiment that transported Bacillus pumilus SAFR-032 bacterial endospores (aliquots visible as small dots on metal coupons) to $\sim 32 \mathrm{~km}$ ASL where conditions mimic Mars. 
Other planets and moons in our solar system also have atmospheres; could they possibly harbor airborne life? After payloads have been developed for collecting microorganisms in Earth's stratosphere, similar technologies could be translated into spacecraft missions sent to Venus or Titan. There is a short but interesting history of interplanetary ballooning with the Vega 1 and 2 probes built by the USSR which plunged into the Venusian atmosphere, inflating at $50 \mathrm{~km}$ above the surface (Preston et al., 1986), operating for about $2 \mathrm{~d}$ and relaying information about wind conditions. It is thought the Venus cloud layer roughly 48 to $65 \mathrm{~km}$ above the surface has environmental conditions within the known tolerances of microbial life on Earth (Irwin and Schulze-Makuch, 2011; Schulze-Makuch et al., 2004; Schulze-Makuch and Irwin, 2002; Smith, 2013). Schulze-Makuch et al. (2004) hypothesized that if life were present on the surface of a habitable Venus billions of years ago, it could have evolved into a permanent airborne ecosystem with sulfur-based acidophilic and phototrophic metabolisms. A simple descent probe containing a life detection payload might be capable of detecting cloud life (Chassefière et al., 2012; Schulze-Makuch and Irwin, 2002). It would be prudent for such spacecraft instrumentation to be developed and tested in Earth's stratosphere before flying to Venus.

\subsection{Space Biology Research Topics in the Stratosphere}

Space Biology is a discipline focused on the response of terrestrial model organisms to the space environment. One of the primary motivations of NASA space biology research is to prepare for safer, long duration human exploration missions beyond LEO. Unknown biological responses in deep space include higher radiation levels of differing quality, microgravity, confinement, and disrupted circadian rhythms (Horneck, 1992). The low dose, broad-spectrum radiation present in Earth's stratosphere, combined with the potential for long duration exposures on balloon missions, offers a unique opportunity for performing space biology radiation studies (Cucinotta et al., 2001; Schimmerling, 2007). For a human crew sent to Mars, cell membranes, organelles, proteins and other essential molecules could be influenced, damaged, or even destroyed from energy-rich galactic or solar cosmic radiation. Although NASA does not yet have an established history of space biology balloon payloads, Europe has been more active in this area. For instance, Wiese et al. (1988) sent erythroleukemic human cell line K562 on a stratospheric balloon flight to discriminate between the effects of microgravity and cosmic radiation on prepared cultures. Another mission described by Galleri et al. (2003) exposed human endothelial cells and $T$ lymphocytes to cosmic radiation on the BRICA2 stratosphere mission inside containers maintaining liquid cultures at $37^{\circ} \mathrm{C}$. Launched from Trapani Milo, Italy, in June 2002, the BRICA2 balloon drifted across the Mediterranean Ocean, then landed in Spain $22 \mathrm{~h}$ later.

Instruments for space biology research could also benefit from balloon flights to the stratosphere. Demonstrated performance in the extreme environment of near space would drive technology readiness level (TRL) forward at a lower cost compared to orbital flight opportunities. For example, NASA is evaluating a miniaturized DNA sequencer that could be used to identify microorganisms in air, water, and surfaces of spacecraft (John et al., 2016). However, the sequencing instrument depends on biological nanopores that measure picoamp changes in electrical current as nucleotide sequences of DNA strands pass through a membrane. Effects of complex radiation levels on instrument performance are unknown but testable with balloon flight experiments to the stratosphere.

\section{PART 3: CONSIDERATIONS FOR FUTURE BIOLOGICAL EXPERIMENTS}

\subsection{How to Get Onboard}

Due to the scarcity of previously flown NASA biological balloon missions, it can be difficult to decipher the "path to flight" for new investigators proposing life science experiments. NASA BPO flies science that is funded by NASA Announcements of Opportunity (AO) or special projects (usually on a cost reimbursement basis). The BPO also supports missions of opportunity at little to no cost to the experimenter, on a spaceavailable basis for small "piggyback" rides on other missions, such as NASA balloon technology 
test flights. While BPO/CSBF will work to achieve piggyback science requirements to the greatest extent possible, these payloads have no precedence over primary mission requirements, nor any guarantee of being accommodated on any fixed schedule. Generally, NASA BPO/CSBF accommodate several piggyback requests each year. Piggyback payloads must not interfere with the primary mission. Thus, piggyback payloads tend to be simple and small, with little or no power demands and no need for extensive support from CSBF personnel.

Biological investigations seeking a dedicated balloon flight can pursue funding avenues in the NASA Science Mission Directorate (SMD), Science Technology Mission Directorate (STMD), and Human Exploration and Operations Mission Directorate (HEOMD). When responding to NASA AOs, investigators should follow instructions in the NASA Guidebook for Proposers (http://www.hq.nasa.gov/office/ procurement/nraguidebook/). Some example target areas are listed below; these do not represent official NASA guidance, but rather, a simple look across existing solicitations potentially relevant to biological ballooning.

Annually, SMD releases the Research Opportunities in Space and Earth Sciences (ROSES) omnibus NASA Research Announcement (NRA), which solicits basic and applied research proposals for flight investigations, including experiments using balloons provided by the BPO. Through the ROSES omnibus, elements relevant to biological balloon teams might fit into areas of Earth Science and Planetary Science. For example, Earth Science elements include Terrestrial Ecology, Biodiversity, and Interdisciplinary Science; Planetary Science elements include Exobiology, Planetary Instrument Concepts for the Advancement of Solar System Observations (PICASSO), and Planetary Protection Research. Regardless of the element, proposers are encouraged to contact the NASA BPO to discuss prospective experiments and to evaluate the technical feasibility of a novel payload concept during the proposal process. If a SMD proposal passes peer review, a NASA program officer will evaluate the need for a balloon flight and with $\mathrm{BPO} / \mathrm{CSBF}$ determine whether a mission can be provided.
For biology teams developing life science instruments that could benefit from a trip to near space, STMD is another avenue to consider. The NASA Flight Opportunities Program (FOP) aims to develop technologies for spaceflight missions (http://www.nasa.gov/flightopportunities).

Research teams external to NASA are eligible for balloon flight opportunities announced twice per year in the SpaceTech-REDDI Umbrella NRA, Appendix F1 (Technology Advancement Using Suborbital Flight Opportunities). One major difference between flights through the FOP compared to SMD awards is that commercial balloon flight providers can be contracted to perform the mission. Two companies currently supporting the FOP with large scientific balloon flights include Near Space Corporation in Tillamook, Oregon (http://nsc.aero/) and World View in Tucson, Arizona (http://worldview.space/). For internal NASA research teams, STMD solicits calls for suborbital flight proposals quarterly. Interested investigators should contact the FOP early in the project timeline to discuss flight opportunities, scheduled campaigns, and the feasibility of a candidate payload.

NASA's Space Biology Program (http://www.nasa.gov/content/space-biologyprogram), managed within the Space Life and Physical Sciences Research and Applications Division of the HEOMD, appears positioned to support biological balloon payloads in the near future. Language in the 2016 Research Opportunities in Space Biology (ROSBio) omnibus NRA included scientific balloon flights as a platform for performing research. In 2017, it is anticipated that NRA NNH16ZTT001N Appendix "Space Biology Research Utilizing Antarctic Balloon Flight Campaigns" within the ROSBio omnibus will be released. Measuring how terrestrial micro-organisms, plants, or animal tissues respond or adapt to environmental stressors, including the broad radiation spectrum encountered in Earth's stratosphere, can address knowledge gaps prioritized by the Space Biology Program.

Student-built balloon payloads from universities, colleges, and minority-serving institutions across the US and Canada are also flown annually by the NASA BPO through the High Altitude Student Platform (HASP), managed 
by the Louisiana Space Consortium. Over the past decade, 10 conventional balloon flights have sent payloads developed by undergraduate and graduate students to near space. It is common for HASP-funded student projects to propose, design, test, fly, and analyze a payload within one yearan exceptional quality of scientific ballooning in general-but particularly valuable for students whose time on campus does not often outlast the schedule for launching an orbital payload project. Each HASP mission provides a standard interface with power, telemetry, commands, and imagery; a gondola supports up to 4 large payloads ( $20 \mathrm{~kg}$ ) and 8 small payloads $(\sim 3 \mathrm{~kg})$. Applications for HASP flight opportunities are usually due in December with selections made by January. Flights occur at Ft. Sumner in late August or early September, averaging about $12 \mathrm{~h}$ in the stratosphere. Of the 110 payloads flown to date through HASP, 11 performed biological sampling or measured effects of the upper atmosphere on specimens carried inside experimental containers (G. Guzik, personal communication). The relatively high portion of student groups flying life science payloads demonstrates the next generation of researchers have a clear interest in the field of biological ballooning.

\subsection{NASA BPO Flight Application for Biological Payloads}

Prospective teams should contact the NASA $\mathrm{BPO}$ and CSBF to receive and submit applications for conventional and LDB flights. Official NASA authorization for both primary and piggyback candidate payloads begins with the flight application, typically announced in April or May and due in mid-June. Field campaigns are planned 2 years in advance for LDB flights, and 1 year out for conventional flights. The BPO seeks applications for both established and pending payloads, regardless of whether the project team has secured funding at the time of submitting an application. Science teams may withdraw an application at any time. Flight applications are reviewed by CSBF and BPO, then added to a Candidate Flight Program around July. The final Candidate Flight Program is submitted to NASA Headquarters for selection into the Approved Flight Program.

All specific payload details are not required for each application. However, science teams should include the maximum amount of known information for mission planning purposes, including any unique support or facility requirements not currently provided by the CSBF. Science teams can include photos, publications, or other relevant payload information to supplement the application package. Investigators may contact the BPO and CSBF to obtain guidance for uncertainties and unfamiliar areas within the flight application. Sections for the conventional and LDB flights are essentially identical. The first part of the application covers background information about the scientific payload (name, science area, description in layman's terms, and Principal Investigator (PI) contact information); funding source and contact information; desired flight category (including launch site, arrival date, and requested flight window); float requirements (target altitude, total time at float, day or night for observations); science objectives and minimum success criteria; and a description of required CSBF support (e.g., telemetry, commanding, or recovery). The next portion of the flight application is for describing any required external meteorological support (e.g., radiosonde, ground station, aircraft, or satellite measurements). A payload's dimensions, mass, flight history (if applicable), restrictions on gondola location, and special requirements for the gondola (e.g., rotation or fixed pointing needs) should be summarized next. For most imaginable collection- or exposure-class biological balloon experiments, the uppermost sun-exposed portion of the gondola will be desired. The final section of the flight application asks for information related to ground support and infrastructure (e.g., work station requirements, gas or cryogens), and known details about payload power, telemetry, electronics, and potentially hazardous materials used on the ground or in flight. After a payload is authorized and moved into the Candidate Flight Program, a more comprehensive NASA safety analysis will be requested by the BPO using a Payload Information Form (PIF). Prior to deployment or shipment of science hardware, a ground and flight safety plan containing all pertinent science system information must be completed. This process depends significantly on feedback from the science team on the type of hazards, special considerations, and requirements associated with the experiment. 
Selecting the right model organism can be critical for biological flight applications. First and foremost, specimens should be amenable to the remote CSBF facility/logistical limitations described later in Section 3.3. The NASA $\mathrm{BPO} / \mathrm{CSBF}$ have strict regulations regarding the type of biological organisms that can be introduced to environments potentially encountered during pre-launch, launch, float, landing, and recovery. The BPO works closely with the WFF Environmental Office prior to the campaign to document and evaluate prospective organisms. Simplicity, stability in stasis, and biosafety should be incorporated into experimental designs. Science teams should develop payloads unaffected by long delays. Spaceflight model organisms commonly flown to the ISS might also work for balloon exposureclass experiments: bacterial endospores, desiccated (vegetative) bacteria, fungal spores or yeast, desiccated cyanobacterial cultures or eukaryotes (lichens, algae, moss), small invertebrates (e.g., tardigrades), and plant seeds or thin-sectioned samples from plant and animal tissues. An exposure-class piggyback experiment from the University of Alcala (Spain) flew recently on LDB Test Flight \#667NT in October 2015, carrying a variety of fungal spores to the stratosphere including Amanita muscaria, Entoloma lividum, Boletus edulis, Macrolepiota procera, Pluteus cervinus, Cortinarius sp., Lactarius deliciosus, Agaricus xanthodermus, Pisolithus arrhizus, Coprinus comatus, Calvatia fragilis, and Mycenastrum corium; results from this study have not yet been published.

Endospores of Bacillus pumilus SAFR-032 bacteria were chosen for the E-MIST experiment (previously described in Section 2.5) from the long list of possible isolates archived from spacecraft assembly clean rooms (Khodadad et al., 2017; Smith et al., 2014). Bacillus pumilus is a Gram-positive, aerobic bacterium which remains stable when sporulated (Benardini et al., 2003; Link et al., 2004; Stepanov et al., 2016). It has a special resistance to extreme conditions including radiation (Gioia et al., 2007) and a naturally derived stasis allowing for easy and early payload integration. The strain also was chosen because it would be harmless to humans and the environment at the concentration flown (approximately $1 \times 10^{10}$ endospores, total, loaded inside the payload). Bacillus pumilus handling can be done at BioSafety Level 1, the lowest possible safety designation with no special operating or disposal requirements needed. An accident destroying the balloon payload would not have introduced an invasive, pathogenic species into the environment, nor would it have impacted CSBF personnel. Moreover, the strain has flown without incident on previous NASA projects (Horneck et al., 2012; Vaishampayan et al., 2012). Despite the low probability of an environmental or health impact, the E-MIST payload provided two levels of containment keeping the strains sequestered from the outside environment except for when the experiment floated in the stratosphere (Smith et al., 2014).

\subsection{Launch Site Facilities, Infrastructure, and Logistics}

NASA provides the balloon, helium, rigging, flight/staging facilities, and all other infrastructure and vehicles required for inflating, launching, tracking, and recovering a balloon. Payload preparations, in contrast, are the responsibility of the science team, with pre-negotiated support requirements established prior to arriving at the launch site. Conventional flights from Ft. Sumner are located at the Ft. Sumner airport, a remote location about $257 \mathrm{~km}$ east of Albuquerque, NM. The CSBF operates out of NASA aircraft hangars and office buildings with basic amenities (power, phone lines, and internet). Areas for preparing payloads are assigned upon science team arrival, and workbenches are generally established with collapsible tables. Extension cords for electronics and tarps or plastic bags for preventing the accumulation of dust in the hangar (or wetness from a passing thunderstorm in the area) are strongly recommended. Some tools can be borrowed from CSBF personnel or purchased in nearby Santa Rosa, NM, but science teams should travel with critical hardware support equipment in-hand. Driving the payload, equipment, and personnel to the field site (instead of traveling by airplane) provides logistical simplification, in addition to flexibility responding to flight delays. Unfavorable weather conditions (high winds, persistent clouds, or precipitation) at either the launch or recovery site can delay a balloon flight indefinitely. At a minimum, science teams should 
expect to spend at least 2 weeks on site at Ft. Sumner.

While CSBF facilities are not equipped for supporting biological research experiments, some relatively simple adaptations can be made to prepare and process payloads in the field. High pedestrian and vehicle traffic at the Ft. Sumner airport has led to an accumulation of dust inside facilities. Airborne dust levels inside the Ft. Sumner hangar for LDB Tech Flight \#651N in August 2014 were 9693 particles per 0.1 cubic ft of air (Met One Particle Counter, Model 229). Comparatively, the outside air was only 5309 particles per 0.1 cubic $\mathrm{ft}$ of air (Smith, unpublished data). Thus, a mobile biological hood or glovebox can be a critical piece of equipment for handling, installing, or preparing specimens. Other potentially worthwhile field equipment for biological teams include: a portable cooler, freezer, or dry ice; pre-sterilized tools (e.g., forceps, Allen wrenches, screws, plastic containers); surface wipes and sterile bench paper for covering tables; and cleaning supplies (e.g., isopropyl alcohol or ethanol, bleach, latex gloves, air canisters/dusters). The simplest biological payload might ship the specimens to the launch site inside the payload already, so no insertion or removal would need to occur in the field reducing the contamination opportunities.

\subsection{Payload Design, Development, and Ground Testing}

The relatively low cost of ballooning permits custom-built payloads that can be built, tested, and flown on a rapid timeline, but NASA also has a variety of space-qualified biological hardware developed for ISS research that could accommodate experiments mounted to a gondola. Whichever payload path is pursued by future teams, an early decision to make in a project is whether the hardware will be standalone (i.e., independent power, command, and control) or integrated with the BPO/CSBF gondola interface. For the latter, a design or modification to existing NASA hardware must meet specifications described by the CSBF (http://www.csbf.nasa.gov /gondoladocs.html) and be verified during the preflight test period at the launch site. Instructions for command and control using the CSBF interface are provided in a user handbook (http://www.csbf.nasa.gov/convdocs.html). Power systems for science must be isolated from the power supply used by BPO/CSBF. Power can be either rechargeable photo-voltaic systems or nonrechargeable primary batteries typical for shorter duration conventional missions. Telemetry rates can vary between tens of $\mathrm{kb} / \mathrm{s}$ to over one $\mathrm{mb} / \mathrm{s}$ depending upon configuration and area of operation. NASA BPO/CSBF works closely with science teams to assess requirements and determine flight configurations system power demands.

Payload position on the gondola is a major consideration that should be incorporated into designs. Most exposure-class experiments will need to be mounted on an outward-facing side of the gondola or the uppermost position. Atmospheric winds cause balloons to rotate slowly, with the flight train also projecting transitory shadows across the gondola. Experiments monitoring the effects of stratospheric sunlight on biological specimens would benefit from including radiometers and dosimeters within payloads to measure the broadest possible range of radiation levels during the mission. To avoid shadowing, experiments could be mounted on a boom extended away from the gondola or through a custom-built or BPOprovided azimuth rotator (G. Garde, personal communication). The Wallops Arc Second Pointer (WASP) System (Kopp et al., 2014) provides arc second biaxial stability for missions but would require additional funding through the science team.

Large hypobaric environmental chamber facilities located at the CSBF in Palestine, TX, can be used to simulate balloon flight profiles and evaluate payload functionality in dry, nearvacuum, thermal extremes. Figure 5 depicts a simplified profile science teams can use for simulating a $12 \mathrm{~h}$ balloon flight launching from Ft. Sumner at sunrise, floating at $32 \mathrm{~km} \mathrm{ASL}$, and eventually descending at sunset. Values were generalized from data acquired on LDB Test Flight \#667NT in October 2015 (Khodadad et al., 2017). Structural and vibration analysis testing is another important pre-flight ground test to ensure payload elements can sustain forces occurring at launch and recovery; transportation of the payload back to the launch site is often done using vehicles on unpaved, bumpy roadways. Payloads are structurally required to be able to sustain an 
impact force of $10 \mathrm{~g}$ vertically loaded and $5 \mathrm{~g}$ transversely loaded to simulate the gondola contacting the ground after a descent on parachute.

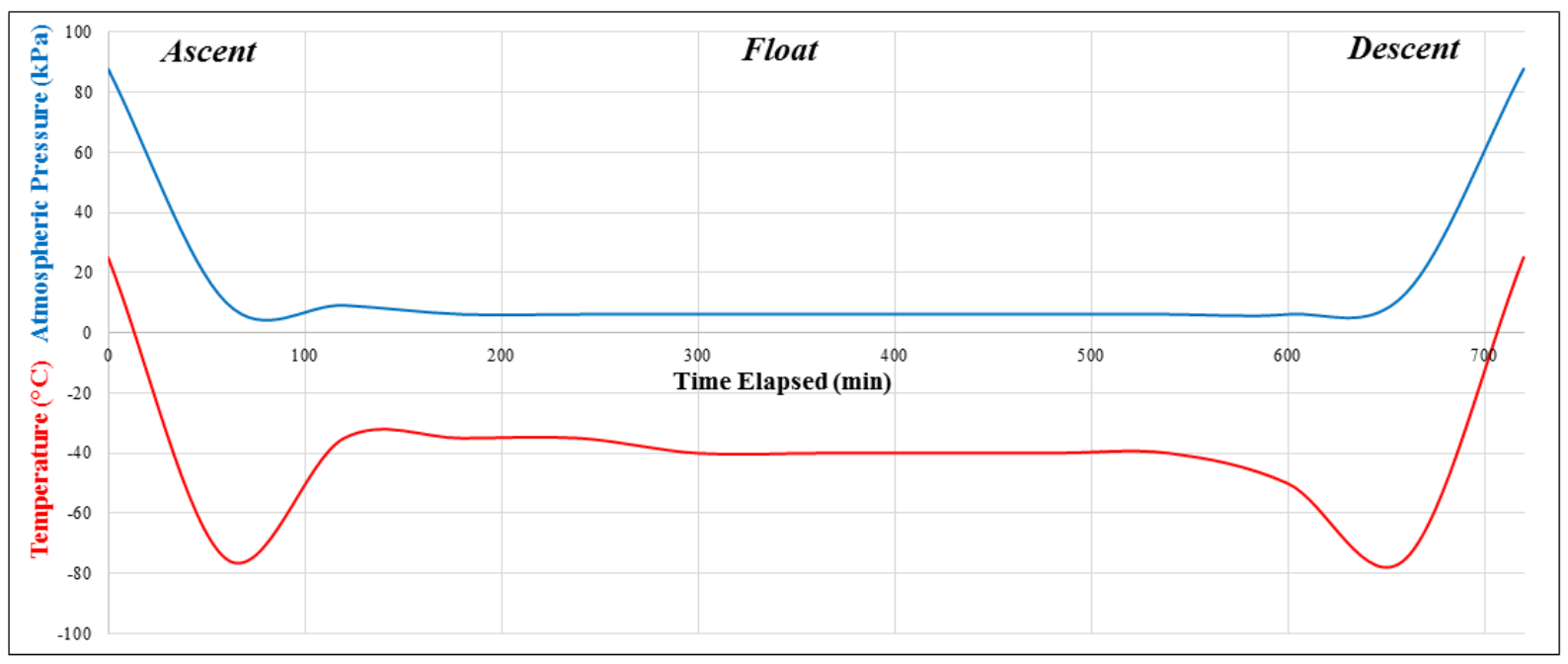

Figure 5. Simplified design for a ground chamber test that would simulate a conventional balloon flight profile. Temperature and pressure conditions shown for a $12 \mathrm{~h}$ flight launching from Ft. Sumner, NM, in autumn (based on data from Test Flight \#667NT).

\section{CONCLUSION}

Many scientific fields have taken advantage of NASA large balloon missions for low cost, long duration access to near space. There is tremendous room for growth in the field of biological ballooning. With this review, we have summarized scientific balloon operations and the flavor of experiments that could be developed with collection- or exposure-class payloads. The stratosphere naturally mimics the Mars surface environment, and flying experiments with balloons avoids limitations often associated with ground simulation chambers and radiation facilities. Earth's stratosphere also has a naturally low and broad background radiation spectrum, with high energy particles establishing a unique spot along the continuum of radiation studies examining the response of biology to LEO and deep space. While our discussion of potential life science experiments, funding opportunities, and payload design considerations was surely not exhaustive, we hope to have conveyed some avenues for pursuing balloon flight opportunities with NASA. A decade from now, if more biologists have flown experiments to the upper atmosphere and published results enriching the fields of aerobiology, astrobiology, and space biology, we will consider this humble ballooning roadmap a success.

\section{ACKNOWLEDGEMENTS}

We thank the NASA BPO and CSBF for previous balloon flight opportunities and their willingness to work with biological payloads. D. Gregory, G. Garde, and D. Fairbrother from the NASA BPO offered invaluable feedback and comments on the operational content of this review, and we are grateful for their time. G. Guzik from Louisiana State University provided useful information about HASP. We would also like to express gratitude to four anonymous reviewers for a comprehensive manuscript evaluation and inputs. Any use of trade names is for descriptive purposes only and does not imply endorsement by the US Government.

\section{REFERENCES}

Acosta-Martinez V, Van Pelt S, Moore-Kucera J, Baddock MC, Zobeck TM (2015) Microbiology of wind-eroded sediments: 
Current knowledge and future research directions. Aeolian Research 18: 99-113

Adams JH, Adcock L, Apple J, Christl M, Cleveand W, Cox M, Dietz K, Ferguson C, Fountain W, Ghita B (2007) Deep space test bed for radiation studies. Nuclear Instruments and Methods in Physics Research Section A: Accelerators, Spectrometers, Detectors and Associated Equipment 579: 522-525

Ballester J, Burns JC, Cayan D, Nakamura Y, Uehara R, Rodó X (2013) Kawasaki Disease and ENSO-driven wind circulation. Geophysical Research Letters 40: 2284-2289

Barberán A, Ladau J, Leff JW, Pollard KS, Menninger HL, Dunn RR, Fierer N (2015) Continental-scale distributions of dustassociated bacteria and fungi. Proceedings of the National Academy of Sciences USA 112: 5756-5761

Beck-Winchatz B, Bramble J (2014) High-altitude ballooning student research with yeast and plant seeds. Gravitational and Space Research 2: 117-127

Benardini JN 3rd, La Duc MT, Beaudet RA, Koukol R (2014) Implementing planetary protection measures on the Mars Science Laboratory. Astrobiology 14: 27-32

Benardini JN, Sawyer J, Venkateswaran K, Nicholson WL (2003) Spore UV and acceleration resistance of endolithic Bacillus pumilus and Bacillus subtilis isolates obtained from Sonoran desert basalt: Implications for lithopanspermia. Astrobiology 3: 709-717

Brownlee D (1978) Microparticle studies by sampling techniques. Cosmic Dust 1: 295336

Brownlee DE, Hodge PW, Bucher W (1973) The physical nature of interplanetary dust as inferred by particles collected at $35 \mathrm{~km}$ (morphology of micrometeorites and ablation products). In Evolutionary and Physical Properties of Meteoroids, CL Hemenway, PM Millman, and AF Cook (eds), pp 291295. Washington, DC: NASA (NASA SP319)

Bryan N, Stewart M, Granger D, Guzik T, Christner B (2014) A method for sampling microbial aerosols using high altitude balloons. Journal of Microbiological Methods 107: 161-168

Burns JC, Cayan DR (2017) The climate-KD link. In Kawasaki Disease, BT Saji, JW Newburger, JC Burns, and M Takahasi (eds), pp 53-57. Tokyo: Springer Japan

Cathey HM (2008) Development overview of the revised NASA ultra long duration balloon. Advances in Space Research 42: 1624-1632

Chassefière E, Wieler R, Marty B, Leblanc F (2012) The evolution of Venus: Present state of knowledge and future exploration. Planetary and Space Science 63: 15-23

Chiu J-L, Boggs S, Chang H-K, Tomsick J, Zoglauer A, Amman M, Chang Y-H, Chou Y, Jean P, Kierans C (2015) The upcoming balloon campaign of the Compton Spectrometer and Imager (COSI). Nuclear Instruments and Methods in Physics Research Section A: Accelerators, Spectrometers, Detectors and Associated Equipment 784: 359-363

Cockell CS, Catling DC, Davis WL, Snook K, Kepner RL, Lee P, McKay CP (2000) The ultraviolet environment of Mars: Biological implications past, present, and future. Icarus 146: $343-359$

Creamean JM, Suski KJ, Rosenfeld D, Cazorla A, DeMott PJ, Sullivan RC, White AB, Ralph FM, Minnis P, Comstock JM (2013) Dust and biological aerosols from the Sahara and Asia influence precipitation in the Western US. Science 339: 1572-1578

CSBF (2016a) Balloon Operations Support: Flight Application Instructions, OF-300-11$\mathrm{H}$ Rev. A., Palestine, TX: Columbia Scientific Balloon Facility

CSBF (2016b) Long-Duration Ballooning: LDB Support for Science Groups, EL-100-10-H Rev. A., Palestine, TX: Columbia Scientific Balloon Facility

Cucinotta FA, Durante M (2006) Cancer risk from exposure to galactic cosmic rays: Implications for space exploration by human beings. Lancet Oncology 7: 431-435

Cucinotta FA, Schimmerling W, Wilson JW, Peterson LE, Badhwar GD, Saganti PB, Dicello JF (2001) Space radiation cancer risks and uncertainties for Mars missions. Radiation Research 156: 682-688 
de Bernardis P, Ade P, Aquilini E, Bock J, Boscaleri A, Cardoni P, Ganga K, Giacometti M, Griffin M, Hanany S (1997) BOOMERanG: Balloon observations of millimetric extragalactic radiation and geophysics. In Microwave Background Anisotropies, FR Bouchet, R Gispert, B Guideroni, and JTT Van (eds), pp 155-160. Singapore: Editions Frontieres

Deleon-Rodriguez N, Lathem TL, Rodriguez RL, Barazesh JM, Anderson BE, Beyersdorf AJ, Ziemba LD, Bergin $M$, Nenes A, Konstantinidis KT (2013) Microbiome of the upper troposphere: Species composition and prevalence, effects of tropical storms, and atmospheric implications. Proceedings of the National Academy of Sciences USA 110: 2575-2580

Della Corte V, Rietmeijer FJ, Rotundi A, Ferrari $M$ (2014) Introducing a new stratospheric dust-collecting system with potential use for upper atmospheric microbiology investigations. Astrobiology 14: 694-705

Favet J, Lapanje A, Giongo A, Kennedy S, Aung YY, Cattaneo A, Davis-Richardson AG, Brown CT, Kort R, Brumsack HJ (2012) Microbial hitchhikers on intercontinental dust: Catching a lift in Chad. The ISME Journal 7: 850-867

Fernstrom A, Goldblatt M (2013) Aerobiology and its role in the transmission of infectious diseases. Journal of Pathogens 2013: Article ID 493960

Fröhlich-Nowoisky J, Kampf CJ, Weber B, Huffman JA, Pöhlker C, Andreae MO, LangYona N, Burrows SM, Gunthe SS, Elbert W (2016) Bioaerosols in the Earth system: Climate, health, and ecosystem interactions. Atmospheric Research 182: 346-376

Galleri G, Camboni MG, Negri R, de Sanctis V, Costanzo G, Meloni MA, Pipia P, Cotronei V, Cogoli A (2003) Stratospheric balloon BIRBA 2 mission: Effects of cosmic radiations on gene expression of human cells. In European Rocket and Balloon Programmes and Related Research, B Warmbein (ed), pp 571-573. Sankt Gallen: European Space Agency

Gioia J, Yerrapragada S, Qin X, Jiang H, Igboeli OC, Muzny D, Dugan-Rocha S, Ding Y, Hawes A, Liu W (2007) Paradoxical DNA repair and peroxide resistance gene conservation in Bacillus pumilus SAFR-032. PLoS One 2: e928

Griffin DW (2007) Non-spore forming eubacteria isolated at an altitude of 20,000 m in Earth's atmosphere: Extended incubation periods needed for culture-based assays. Aerobiologia 24: 19-25

Griffin DW (2004) Terrestrial microorganisms at an altitude of $20,000 \mathrm{~m}$ in Earth's atmosphere. Aerobiologia 20: 135-140

Griffin DW, Kellogg CA, Shinn EA (2001) Dust in the wind: Long range transport of dust in the atmosphere and its implications for global public and ecosystem health. Global Change \& Human Health 2: 20-33

Griffin DW, Westphal DL, Gray MA (2006) Airborne microorganisms in the African desert dust corridor over the mid-Atlantic ridge, Ocean Drilling Program, Leg 209. Aerobiologia 22: 211-226

Hassler DM, Zeitlin C, Wimmer-Schweingruber RF, Ehresmann B, Rafkin S, Eigenbrode JL, Brinza DE, Weigle G, Böttcher S, Böhm E (2014) Mars' surface radiation environment measured with the Mars Science Laboratory's Curiosity Rover. Science 343: 1244797

Horneck G (1992) Radiobiological experiments in space: A review. International Journal of Radiation Applications and Instrumentation. Part D. Nuclear Tracks and Radiation Measurements 20: 185-205

Horneck G, Moeller R, Cadet J, Douki T, Mancinelli RL, Nicholson WL, Panitz C, Rabbow E, Rettberg P, Spry A (2012) Resistance of bacterial endospores to outer space for planetary protection purposes-experiment PROTECT of the EXPOSE-E mission. Astrobiology 12: 445456

Irwin LN, Schulze-Makuch D (2011) Suspended animation. In Cosmic Biology: How Life Could Evolve on Other Worlds, LN Irwin, and D Schulze-Makuch (eds), pp 153-172. New York: Springer

Jacob DJ (1999) Introduction to Atmospheric Chemistry, Princeton: Princeton University Press

John K, Botkin D, Burton A, Castro-Wallace S, Chaput J, Dworkin J, Lehman N, Lupisella 
M, Mason C, Smith D (2016) The biomolecule sequencer project: Nanopore sequencing as a dual-use technology for crew health and astrobiology investigations. In $47^{\text {th }}$ Lunar and Planetary Science Conference, Houston, TX: Lunar \& Planetary Science Institute, \#2982

Jones WV (2014) Evolution of scientific ballooning and its impact on astrophysics research. Advances in Space Research 53: 1405-1414

Jones WV (2012) The US long duration balloon facility at McMurdo Station. Proceedings of the International Astronomical Union 8: 169-177

Kellogg CA, Griffin DW (2006) Aerobiology and the global transport of desert dust. Trends in Ecology \& Evolution 21: 638-644

Kempf MJ, Chen F, Kern R,Venkateswaran K (2005) Recurrent isolation of hydrogen peroxide-resistant spores of Bacillus pumilus from a spacecraft assembly facility. Astrobiology 5: 391-405

Khodadad, CL, Wong, GM, James, LM, Thakrar, PJ, Lane, MA, Catechis, JA, Smith, DJ (2017) Stratosphere conditions inactivate bacterial endospores from a Mars spacecraft assembly facility. Astrobiology 17: 337-350

Kopp G, Belting C, Castleman Z, Drake G, Espejo J, Heuerman K, Lamprecht B, Lanzi J, Smith P, Stuchlik D, Vermeer B (2014) First results from the hyperspectral imager for climate science (HySICS). In SPIE Proceedings, 9088, Algorithms and Technologies for Multispectral, Hyperspectral, and Ultraspectral Imagery XX, M Velez-Reyes and FA Kruse (eds), 90880Q

Kuhn W, Atreya S (1979) Solar radiation incident on the Martian surface. Journal of Molecular Evolution 14: 57-64

Kylling A, Danielsen T, Blumthaler M, Schreder J, Johnsen B (2003) Twilight tropospheric and stratospheric photodissociation rates derived from balloon borne radiation measurements. Atmospheric Chemistry and Physics 3: 377-385

Link L, Sawyer J, Venkateswaran K, Nicholson W (2004) Extreme spore UV resistance of Bacillus pumilus isolates obtained from an ultraclean spacecraft assembly facility. Microbial Ecology 47: 159-163
Maki T, Kakikawa M, Kobayashi F, Yamada M, Matsuki A, Hasegawa H, Iwasaka Y (2013) Assessment of composition and origin of airborne bacteria in the free troposphere over Japan. Atmospheric Environment 74: 73-82

McKay CP, Friedmann EI, Gómez-Silva B, Cáceres-Villanueva L, Andersen DT, Landheim R (2003) Temperature and moisture conditions for life in the extreme arid region of the Atacama Desert: Four years of observations including the El Niño of 1997-1998. Astrobiology 3: 393-406

Mertens CJ, Gronoff GP, Norman RB, Hayes BM, Lusby TC, Straume T, Tobiska WK, Hands A, Ryden K, Benton E, Wiley S, Gersey B, Wilkins R, Xu X (2016) Cosmic radiation dose measurements from the $\mathrm{RaD}-\mathrm{X}$ flight campaign. Space Weather 14: 874-898

Myriokefalitakis S, Fanourgakis G, Kanakidou M (2017) The contribution of bioaerosols to the organic carbon budget of the atmosphere. In Perspectives on Atmospheric Sciences, $\mathrm{T}$ Karacostas, A Bais, and PT Nastos (eds), pp 845-851. New York: Springer

Narlikar J, Lloyd D, Wickramasinghe N, Harris MJ, Turner MP, Al-Mufti S, Wallis MK, Wainwright $\mathrm{M}$, Rajaratnam $\mathrm{P}$, Shivaji S (2003) A balloon experiment to detect microorganisms in the outer space. Astrophysics and Space Science 285: 555562

NASA (2015) NASA Astrobiology Strategy. Washington, DC: National Aeronuatics and Space Administration, NASA/SP-2015-3710

NASA (2014a) Scientific Balloons. Washington, DC: National Aeronautics and Space Administration, NP-2014-9-181-GSFC

NASA (2014b) The Super Pressure Balloon (SPB). Washington, DC: National Aeronuatics and Space Administration, NP2014-9-182-GSFC

NCRP (1989) Guidance on Radiation Received in Space Activities. Bethesda, MD: US National Council for Radiation Protection and Measurements, Report \#98

NCRP (2006) Information Needed to Make Recommendations for Space Missions Beyond Low-Earth Orbit. Bethesda, MD: US National Council for Radiation Protection and Measurements, Report \#153 
NCRP (1995) Radiation Exposure and High Altitude Flight. Bethesda, MD: US National Council for Radiation Protection and Measurements, Commentary \#12

Nicholson WL, Schuerger AC, Setlow P (2005) The solar UV environment and bacterial spore UV resistance: Considerations for Earth-to-Mars transport by natural processes and human spaceflight. Mutation Research 571: $249-264$

Preston LJ, Dartnell LR (2014) Planetary habitability: Lessons learned from terrestrial analogues. International Journal of Astrobiology 13: 81-98

Preston R, Hildebrand C, Purcell G, Ellis J, Stelzried C, Finley S, Sagdeev R, Linkin V, Kerzhanovich V, Altunin V (1986) Determination of Venus winds by groundbased radio tracking of the VEGA balloons. Science 231: 1414-1416

Puspitasari F, Maki T, Shi G, Bin C, Kobayashi F, Hasegawa H, Iwasaka Y (2015) Phylogenetic analysis of bacterial species compositions in sand dunes and dust aerosol in an Asian dust source area, the Taklimakan Desert. Air Quality, Atmosphere \& Health 9: 1-14

Randel WJ, Jensen EJ (2013) Physical processes in the tropical tropopause layer and their roles in a changing climate. Nature Geoscience 6: 169-176

Schimmerling W (2003) Overview of NASA's space radiation research program. Gravitational and Space Biology Bulletin 16: 5-10

Schimmerling W (2011) The space radiation environment: An introduction. THREE, available at: https://three.jsc.nasa.gov/ concepts/SpaceRadiationEnviron.pdf

Schuerger AC, Nicholson WL (2006) Interactive effects of hypobaria, low temperature, and $\mathrm{CO}_{2}$ atmospheres inhibit the growth of mesophilic Bacillus spp. under simulated martian conditions. Icarus 185: 143-152

Schuerger AC, Nicholson WL (2016) Twenty species of hypobarophilic bacteria recovered from diverse soils exhibit growth under simulated martian conditions at $0.7 \mathrm{kPa}$. Astrobiology 16: 964-976

Schulze-Makuch D, Grinspoon DH, Abbas O, Irwin LN, Bullock MA (2004) A sulfurbased survival strategy for putative phototrophic life in the Venusian atmosphere. Astrobiology 4: 11-18

Schulze-Makuch D, Irwin LN (2002) Reassessing the possibility of life on Venus: Proposal for an astrobiology mission. Astrobiology 2: 197-202

Shivaji S, Chaturvedi P, Suresh K, Reddy GS, Dutt CB, Wainwright M, Narlikar JV, Bhargava PM (2006) Bacillus aerius sp. nov., Bacillus aerophilus sp. nov., Bacillus stratosphericus sp. nov. and Bacillus altitudinis sp. nov., isolated from cryogenic tubes used for collecting air samples from high altitudes. International Journal of Systematic and Evolutionary Microbiology 56:1465-1473

Smets W, Moretti S, Denys S, Lebeer S (2016) Airborne bacteria in the atmosphere: Presence, purpose, and potential. Atmospheric Environment 139: 214-221

Smith DJ (2013) Microbes in the upper atmosphere and unique opportunities for astrobiology research. Astrobiology 13: 981990

Smith DJ, Griffin DW, McPeters RD, Ward PD, Schuerger AC (2011) Microbial survival in the stratosphere and implications for global dispersal. Aerobiologia 27: 319-332

Smith DJ, Griffin DW, Schuerger AC (2009) Stratospheric microbiology at $20 \mathrm{~km}$ over the Pacific Ocean. Aerobiologia 26: 35-46

Smith DJ, Jaffe DA, Birmele MN, Griffin DW, Schuerger AC, Hee J, Roberts MS (2012) Free tropospheric transport of microorganisms from Asia to North America. Microbial Ecology 64: 973-985

Smith DJ, Thakrar PJ, Bharrat AE, Dokos AG, Kinney TL, James LM, Lane MA, Khodadad CL, Maguire F, Maloney PR (2014) A balloon-based payload for Exposing Microorganisms in the Stratosphere (EMIST). Gravitational and Space Research 2: 70-80

Smith DJ, Timonen HJ, Jaffe DA, Griffin DW, Birmele MN, Perry KD, Ward PD, Roberts MS (2013) Intercontinental dispersal of bacteria and archaea by transpacific winds. Applied and Environmental Microbiology 79: 1134-1139 
Solomon S (1999) Stratospheric ozone depletion: A review of concepts and history. Reviews of Geophysics 37: 275-316

Stepanov VG, Tirumalai MR, Montazari S, Checinska A, Venkateswaran K, Fox GE (2016) Bacillus pumilus SAFR-032 genome revisited: Sequence update and re-annotation. PloS One 11: e0157331

Vaishampayan P, Probst AJ, La Duc MT, Bargoma E, Benardini JN, Andersen GL, Venkateswaran K (2013) New perspectives on viable microbial communities in lowbiomass cleanroom environments. The ISME Journal 7: 312-324

Vaishampayan PA, Rabbow E, Horneck G, Venkateswaran KJ (2012) Survival of Bacillus pumilus spores for a prolonged period of time in real space conditions. Astrobiology 12: 487-497

Wainwright M, Wickramasinghe N, Narlikar J, Rajaratnam P (2003) Microorganisms cultured from stratospheric air samples obtained at $41 \mathrm{~km}$. FEMS Microbiology Letters 218: 161-165

Ward JE (2013) The Super-TIGER instrument to probe galactic cosmic-ray origins. Bulletin of the American Physical Society 58: L14.008

Wiese C, Bechler B, Lorenzi G, Cogoli A (1988) Cultures of erythroleukemic cells (K-562) on a stratospheric balloon flight. In Terrestrial Space Radiation and Its Biological Effects, PD McCormack, CE Swenberg, and $\mathrm{H}$ Bucker (eds), pp 337-343. New York: Springer

Wynn-Williams D, Edwards H (2000) Antarctic ecosystems as models for extraterrestrial surface habitats. Planetary and Space Science 48: 1065-1075

Yamaguchi N, Baba T, Ichijo T, Himezawa Y, Enoki K, Saraya M, Li P-F, Nasu M (2016) Abundance and community structure of bacteria on asian dust particles collected in Beijing, China, during the Asian dust season. Biological and Pharmaceutical Bulletin 39: 68-77

Yamaguchi N, Ichijo T, Sakotani A, Baba T, Nasu M (2012) Global dispersion of bacterial cells on Asian dust. Scientific Reports 2: 525

Yu H, Remer LA, Chin M, Bian H, Tan Q, Yuan T, Zhang Y (2012) Aerosols from overseas rival domestic emissions over North America. Science 337: 566-569

Zurek RW, Barnes JR, Haberle RM, Pollack JB, Tillman JE, Leovy CB (1992) Dynamics of the atmosphere of Mars. In Mars, HH Kieffer, BM Jakosky, CW Snyder, and MS Mathews (eds), pp 835-933. Tucson: University of Arizona Press 